\title{
Selective Identification of Macrophages and Cancer Cells Based on Thermal Transport through Surface-Imprinted Polymer Layers
}

\author{
Kasper Eersels, ${ }^{\dagger, \nabla}$ Bart van Grinsven, ${ }^{\dagger, \nabla}$ Anitha Ethirajan, ${ }^{\dagger}$ Silke Timmermans, ${ }^{\dagger}$
}

Kathia L. Jiménez Monroy, ${ }^{\dagger}$ Jeroen F. J. Bogie, ${ }^{\dagger}$ Sathya Punniyakoti, ${ }^{\dagger}$ Thijs Vandenryt, ${ }^{\S}$

Jerome J. A. Hendriks, ${ }^{\ddagger}$ Thomas J. Cleij, ${ }^{\dagger, \|}$ Mat J. A. P. Daemen, ${ }^{\perp}$ Veerle Somers, ${ }^{\ddagger}$ Ward De Ceuninck, ${ }^{\dagger, \#}$ and Patrick Wagner*, ${ }^{\dagger}, \#$

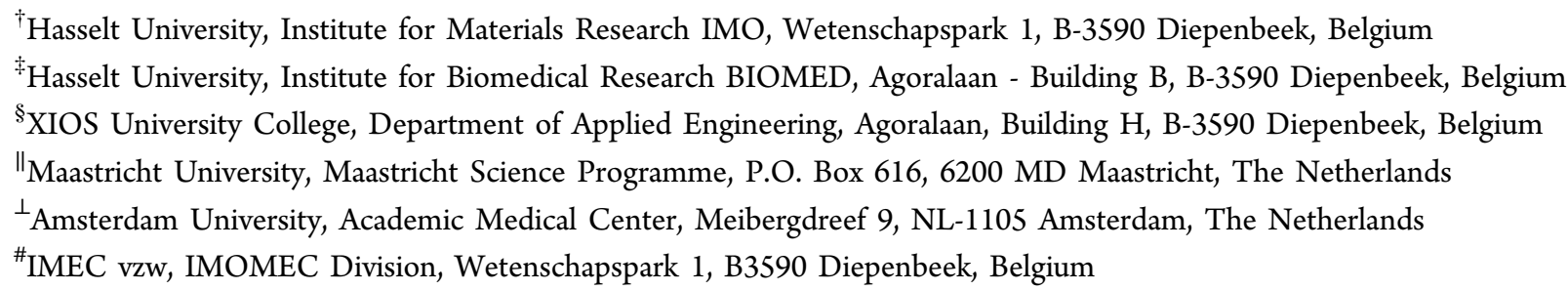

Supporting Information

ABSTRACT: In this article, we describe a novel straightforward method for the specific identification of viable cells (macrophages and cancer cell lines MCF-7 and Jurkat) in a buffer solution. The detection of the various cell types is based on changes of the heat transfer resistance at the solid-liquid interface of a thermal sensor device induced by binding of the cells to a surface-imprinted polymer layer covering an aluminum chip. We observed that the binding of cells to the polymer layer results in a measurable increase of heat transfer resistance, meaning that the cells act as a thermally insulating layer. The detection limit was found to be on the order of $10^{4}$ cells $/ \mathrm{mL}$, and

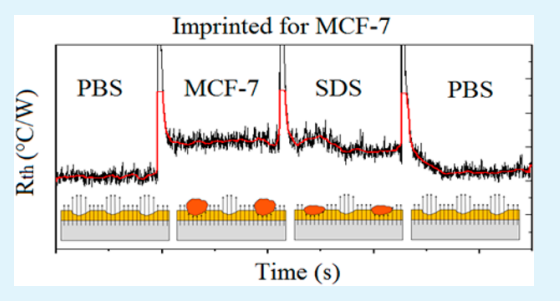
mutual cross-selectivity effects between the cells and different types of imprints were carefully characterized. Finally, a rinsing method was applied, allowing for the specific detection of cancer cells with their respective imprints while the cross-selectivity toward peripheral blood mononuclear cells was negligible. The concept of the sensor platform is fast and low-cost while allowing also for repetitive measurements.

KEYWORDS: heat transfer resistance, surface-imprinted polymer, biomimetic sensors, macrophages, NR8383, RAW 264.7 cell lines, MCF-7 cell lines, Jurkat cell lines

\section{INTRODUCTION}

Molecularly imprinted polymers (MIPs) are able to detect chemical substances in complex matrices and therefore gain increasing attention in bioanalytical applications. ${ }^{1-5}$ The advantages of MIPs include easy and cheap synthesis, chemical and thermal stability, reusability, and an unlimited shelf life. ${ }^{6}$ In recent years, the concept of molecular imprinting has been extended to surface imprinting of thin polymer films with proteins, ${ }^{7,8}$ bacteria, ${ }^{9-11}$ viruses, ${ }^{8,12}$ pollen grains, ${ }^{13}$ yeast, ${ }^{14}$ HeLa cells, ${ }^{15}$ and erythrocytes. ${ }^{8,16}$ In this work, surfaceimprinted polyurethane layers (SIPs) are used for the selective detection of rodent macrophages (proof-of-principle) and human cancer cells (medically relevant application). Surfaceimprinted cell receptors may also be an added value for the emerging field of cell-based biosensors in which the cells themselves act as a transducer element. ${ }^{17-19}$ The identification of cells by sensor devices is commonly based on microbalances, ${ }^{16}$ electronic read-out, ${ }^{20,21}$ or microfluidic techniques. $^{22}$ These concepts require advanced equipment; hence, a low-cost automated sensor platform allowing distinguishing cells on basis of their size, shape, or membrane functionalities is of high relevance. We will show that the heat transfer method (HTM), developed recently in the context of DNA mutation analysis, ${ }^{23}$ can be readily combined with SIP-type synthetic cell receptors, where selectivity is provided by the SIP layer and the readout requires no more than a controlled heat source and two temperature sensors.

There are various examples where the precise shape of cells and membrane structure correlate with certain physiological conditions or diseases; slight variations in the density of carbohydrate antigens of the $\mathrm{ABO}$ system on the glycocalyx of erythrocytes determine the blood group and Rhesus factor of mammals. ${ }^{24,25}$ Furthermore, the shape of the erythrocytes can also be characteristic for diseases such as sickle cell anemia. ${ }^{26}$ Using SIPs as sensitive layers on quartz crystal microbalances (QCM), Dickert's group succeeded in ABO phenotyping of erythrocytes without any labeling. ${ }^{16}$ The best discrimination was found for $\mathrm{AB}$-imprinted SIPs, showing a $25 \%$ response

Received: April 30, 2013

Accepted: July 2, 2013

Published: July 2, 2013 
Scheme 1. General Measurement Concept. (a) Schematics of the measuring setup, not drawn to scale. The aluminum substrate covered with the SIP is attached to the copper block. The temperature of the copper block $T_{1}$ is kept constant at $37.0{ }^{\circ} \mathrm{C}$, and the temperature $T_{2}$ of the liquid is monitored in time. (b) Illustration of cell binding to the binding cavities of the SIP, thereby blocking the heat transfer from the chip to the liquid.
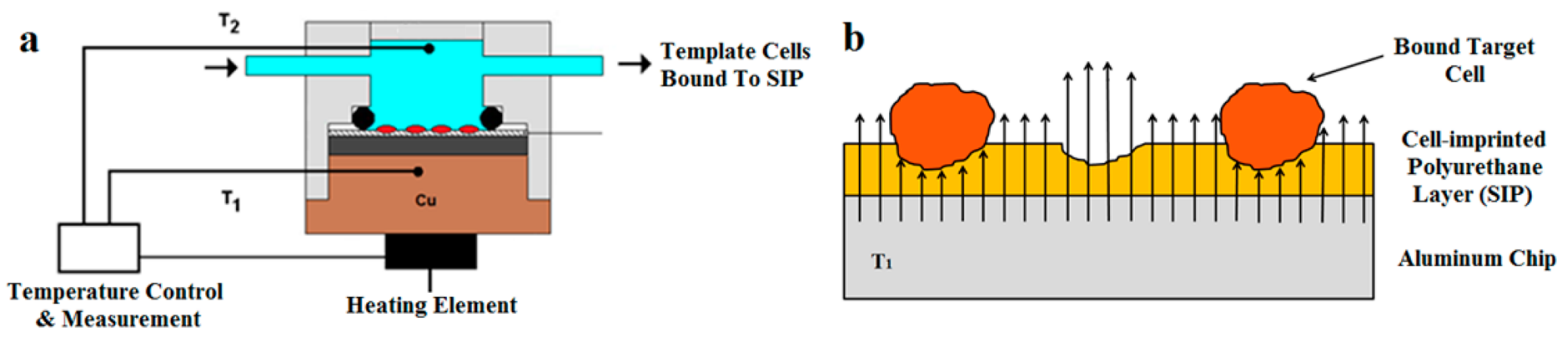

when exposed to O-type cells as compared to the $100 \%$ response upon binding of $\mathrm{AB}$ cells. The sensor platform proposed in our work also focuses on the identification of circulating blood cells, differing either in size, shape, or membrane functionalities. This offers potential for screening of cardiovascular diseases and cancer, which are prevalent causes of death in Western society.

In case of cancer, it is well known that overexpression of certain antigens on the membrane is indicative of tumor formation. ${ }^{27}$ An example is the glycoprotein MUC1 (Mucin 1 cell surface associated protein), which displays extensive $\mathrm{O}$ linked glycosylation on its extracellular domain. MUC1 lines epithelial cells and overexpression of MUC1 is associated with colon, lung, pancreatic, ovarian, and breast cancers as well as blood cell lymphomas. ${ }^{27,28}$ A breast cancer cell line with strong overexpression of MUC1, used in the experiments described below, is MCF-7. ${ }^{29}$ This will be compared to Jurkat cells, an immortalized T-lymphocyte cell line related to leukemia. ${ }^{30}$ The MUC1 overexpression of Jurkat cells is less pronounced as compared to MCF-7, while both spherical cell types have the same diameter of about $20 \mu \mathrm{m}$. As a control, MCF-7 and Jurkat imprints will also be exposed to peripheral blood mononuclear cells (PBMC) of a healthy test person.

Macrophages, used in this study for proof-of-concept purposes, also deserve attention because their shape, and membrane groups can be related to cardiovascular disorders. For example, macrophages in atherosclerosis patients display different antigens (including survivin) on their membranes as compared to macrophages of healthy individuals. ${ }^{31,32}$ In our concept study, two different types of macrophages will be employed: rat alveolar macrophages (cell line NR8383) and mouse leukemic monocyte macrophages (cell line RAW 264.7).

\section{EXPERIMENTAL METHODS}

2.1. Design of Sensor Setup. The sensor setup shown in Scheme 1a has been described in earlier work on the thermal denaturation of double-stranded DNA for the detection of single nucleotide polymorphisms. ${ }^{23}$ The polyurethane-covered aluminum substrates $(10 \mathrm{~mm} \times 10 \mathrm{~mm} \times 1.0 \mathrm{~mm})$ were horizontally mounted in a homemade flow cell of $110 \mu \mathrm{L}$ (liquid contact area of $28 \mathrm{~mm}^{2}$, liquid height of $4.0 \mathrm{~mm}$ ). The substrates were fixed mechanically onto a copper backside contact of the device, and heat-conductive paste was used to optimize the thermal contact between the copper and the aluminum chips. Liquids were exchanged either manually or automatically, using a syringe-driven flow system (ProSense, model NE-500, The Netherlands). All thermal resistance measurements were performed under static conditions without liquid flow. Two miniaturized thermocouples (type $\mathrm{K}$, diameter $500 \mu \mathrm{m}$, TC Direct, The Netherlands) were used for monitoring the temperature $T_{1}$ of the copper backside contact and the temperature $T_{2}$ of the solution in the center of the flow cell at a position $1.7 \mathrm{~mm}$ above the chip surface. Heat flow was generated with a power resistor $(22 \Omega$, MPH20, Farnell, Belgium) attached to the copper block using heat-conductive paste and tightly fixed with a screw. The thermocouple signals were collected in a data acquisition unit (Picolog TC08, Picotech, U.K.) and further processed by a PID controller (parameters: $P=10, I=5, D=$ 0.1 ) in order to regulate $T_{1}$. The output voltage calculated by the PID controller was fed back into the power resistor via a second controller (NI USB 9263, National Instruments, U.S.A.) and a power operational amplifier (LM675, Farnell, Belgium). The sampling rate of the $T_{1}$ and $T_{2}$ values was one measurement per second. All measurements were performed in a temperature-stabilized environment at an ambient temperature of $19.0{ }^{\circ} \mathrm{C}$.

2.2. Protocol for Preparing Cell-Imprinted Polyurethane Layers. Polyurethane layers were formed by dissolving $122 \mathrm{mg}$ of 4,4'diisocyanatodiphenylmethane, $222 \mathrm{mg}$ of bisphenol A, and $25 \mathrm{mg}$ of phloroglucinol in $500 \mu \mathrm{L}$ of anhydrous tetrahydrofuran (THF). All reagents were used as received from Sigma-Aldrich N.V. (Diegem, Belgium) and had a purity of minimally $99.9 \%$. This mixture was stirred at $65{ }^{\circ} \mathrm{C}$ for $200 \mathrm{~min}$ under an inert nitrogen atmosphere until the polymer solution reached its gelling point. Then, the solution was diluted in a 1:5 ratio in THF and spin-coated during $60 \mathrm{~s}$ at $2000 \mathrm{rpm}$ onto $1 \mathrm{~cm}^{2}$ aluminum substrates. This resulted in polyurethane layers with an average thickness of $1.2 \mu \mathrm{m} \pm 0.1 \mu \mathrm{m}$ as measured with a profilometer (Dektak3ST, Sloan Instruments Corporation, Santa Barbara, U.S.A.). In parallel, homemade polydimethylsiloxane (PDMS) stamps were covered with cells in order to stamp the cells into the spin-coated polyurethane layer. PDMS stamps were made using the Sylgard 184 silicone elastomer kit (Malvom N.V., Schelle, Belgium). Cell suspension in PBS buffer (phosphate-buffered saline solution, $400 \mu \mathrm{L}$ ) was applied to the PDMS stamp. After $50 \mathrm{~s}$ of sedimentation time, the excess fluid was removed by spinning at 3000 $\mathrm{rpm}$ for $60 \mathrm{~s}$ in order to create a dense monolayer of cells on the stamp surface. The cell-covered stamp was gently pressed (pressure of $70 \mathrm{~Pa}$ ) onto the polyurethane layer and cured for $18 \mathrm{~h}$ at $65{ }^{\circ} \mathrm{C}$ under nitrogen atmosphere. After curing, the stamp was removed from the surface. By rinsing the surface with $0.1 \%$ sodium dodecylsulfate solution and PBS, the template cells were washed off from the polymer layer, leaving behind selective binding cavities on the polyurethane surface. Nonimprinted polymer layers, used for assessing specificity, were made exactly in the same way as their imprinted counterparts, however without covering the PDMS stamp with template cells.

2.3. Culturing of Cells. Mouse leukemic monocyte macrophage RAW 264.7 cells (American-type culture collection ATCC: TIB-71), rat alveolar macrophage NR8383 cells (ATCC: CRL-2192), and human Jurkat cells (ATCC: TIB-152) were cultured in Roswell Park Memorial Institute medium (RPMI medium, Lonza Braine S.A., Braine-l'Alleud, Belgium). Cells were passaged at a confluence of about $80 \%$. Prior to imprinting and measurements, the RPMI medium was exchanged with phosphate buffered saline (PBS) in six washing steps in order to remove proteins of the culture medium. Saccharomyces cerevisiae solutions were made by dissolving compressed baker's yeast from Dr. Oetker (Bielefeld, Germany) in a PBS buffer solution. Cell counting to determine the cell concentration in buffer 

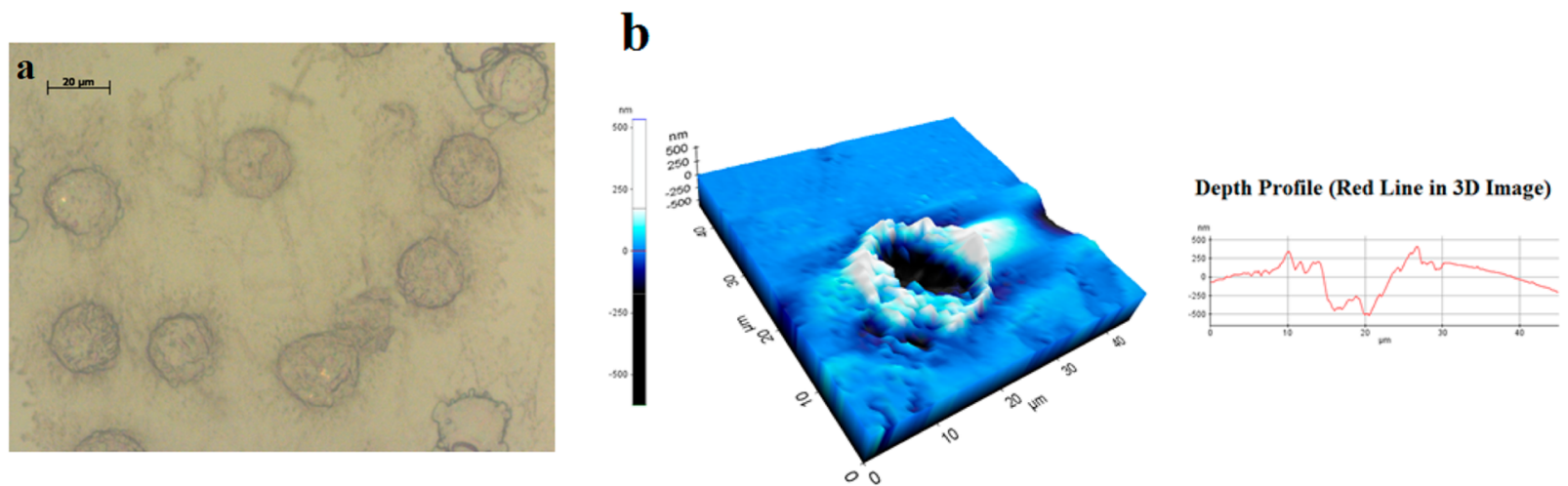

Figure 1. Structural analysis of a SIP imprinted for human MCF-7 breast cancer cells. (a) Optical micrograph of a typical SIP imprinted for MCF-7 breast cancer cells. (b) Atomic force microscopy on a single MCF-7 imprint shown as a 3D representation together with a cross sectional depth profile of the imprint.
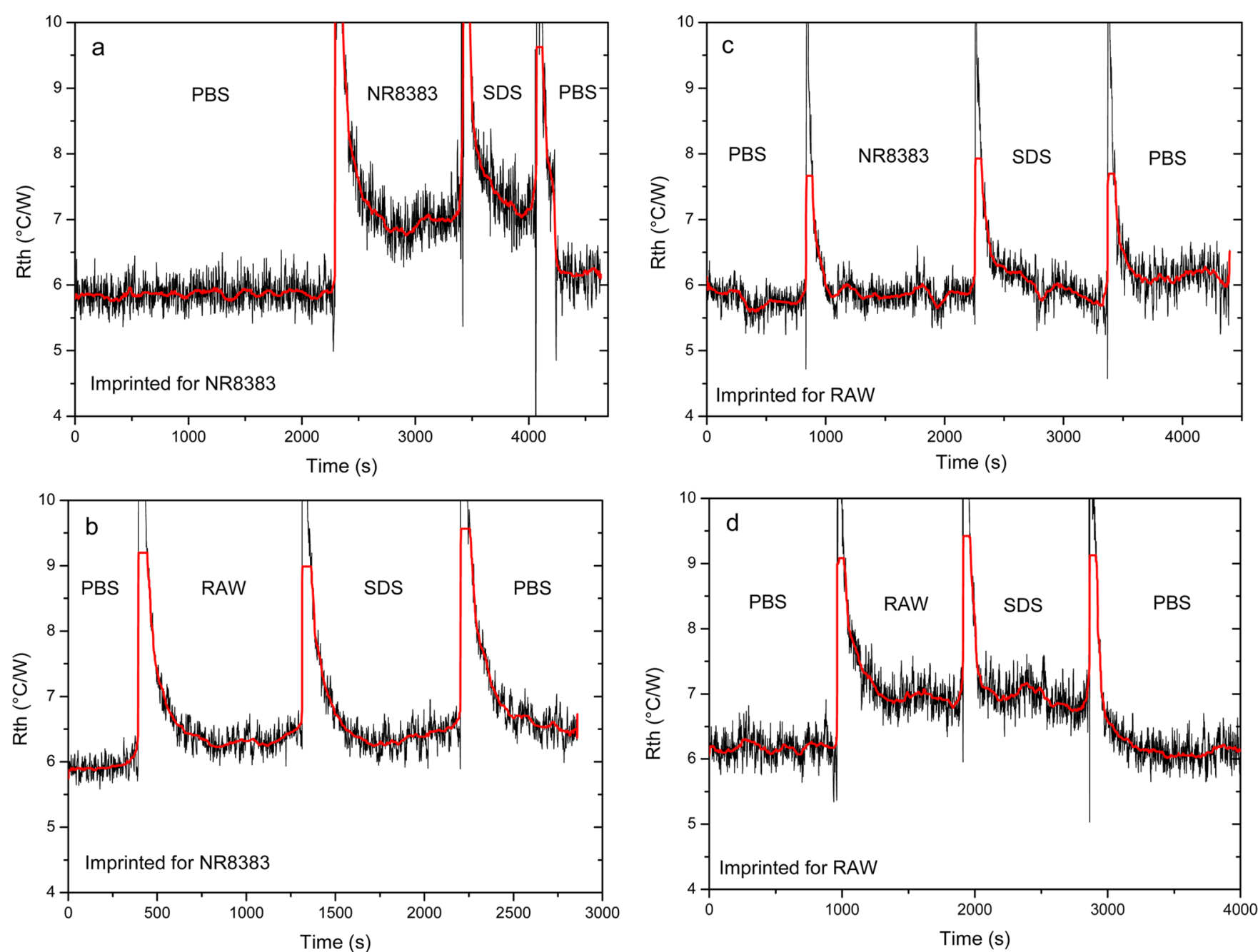

Figure 2. Macrophage detection in a cross-selectivity experiment (proof-of-principle). The setup was used to selectively discriminate between rat (NR8383) and mouse (RAW 264.7) macrophage cell lines. SIPs were prepared for both cell types, and the $R_{\text {th }}$ response to both target cells is studied. The system was stabilized in a PBS buffer solution of pH 7.4 (denoted PBS) before addition of the target cells (PBS, concentration $1 \times 10^{6}$ cells $/ \mathrm{mL}$ ). After rinsing with $0.1 \%$ sodium dodecyl sulfate solution (SDS), the system was stabilized again before flushing the liquid compartment with PBS buffer. (a) Time dependence of the thermal resistance for a SIP imprinted with NR8383 cells using NR8383 as target cells. The black line presents the raw data; the red line was obtained with a 50 data point percentile filter. (b) Time-dependent $R_{\mathrm{th}}$ response for the NR8383 SIP when exposed to RAW 264.7 cells. (c) Time-dependent $R_{\text {th }}$ signal of a SIP imprinted for RAW 264.7 cells upon exposure to NR8383 cells. (d) Recognition of NR8383 cells with a NR8383 imprinted SIP layer.

medium was done using a hemocytometer (VWR International, Leuven, Belgium). MCF-7 cells (ATCC: HTB-22) were cultured in
Eagle's minimum essential medium (EMEM medium, Lonza Braine S.A.). They were passaged and washed as described above for other 
Table 1. Absolute and Relative Sensor Response of NR8383, RAW 264.7, andYeast Imprints When Exposed to Standardized Concentrations of These Three Cell Types without Washing steps ${ }^{a}$

\begin{tabular}{|c|c|c|c|c|c|c|}
\hline \multirow[t]{2}{*}{$\begin{array}{l}\text { Target } \\
\text { Concentration }\end{array}$} & \multicolumn{2}{|c|}{$\begin{array}{l}\text { NR8383 } \\
1 \cdot 10^{6} \pm 8 \cdot 10^{4} \text { cells } / \mathrm{ml}\end{array}$} & \multicolumn{2}{|c|}{$\begin{array}{l}\text { RAW } 264.7 \\
1 \cdot 10^{6} \pm 9 \cdot 10^{4} \text { cells } / \mathrm{ml}\end{array}$} & \multicolumn{2}{|c|}{$\begin{array}{l}\text { Saccharomyces cerevisiae } \\
1 \cdot 10^{6} \pm 9 \cdot 10^{4} \text { cells } / \mathrm{ml}\end{array}$} \\
\hline & $\Delta \mathrm{R}$ th $\left({ }^{\circ} \mathrm{C} / \mathrm{W}\right)$ & $\%$ response & $\Delta$ Rth $\left({ }^{\circ} \mathrm{C} / \mathrm{W}\right)$ & $\%$ response & $\Delta \mathrm{R}$ th $\left({ }^{\circ} \mathrm{C} / \mathrm{W}\right)$ & $\%$ response \\
\hline $\begin{array}{l}\text { Imprint: NR8383 } \\
7,900 \pm 440 \text { cavities } / \mathrm{cm}^{2}\end{array}$ & $1.14 \pm 0.2$ & $19.5 \pm 3.5$ & $-0.18 \pm 0,1$ & $-2.8 \pm 2$ & $-0.18 \pm 0.04$ & $-3.1 \pm 0.7$ \\
\hline $\begin{array}{l}\text { Imprint: RAW } 264.7 \\
21,650 \pm 8,760 \text { cavities } / \mathrm{cm}^{2}\end{array}$ & $0.10 \pm 0.2$ & $1.79 \pm 2,8$ & $0.85 \pm 0.2$ & $13.9 \pm 3.2$ & $0.14 \pm 0.2$ & $2.4 \pm 5.4$ \\
\hline $\begin{array}{l}\text { Imprint: Saccharom. cerevisiae } \\
183,220 \pm 54,230 \text { cavities } / \mathrm{cm}^{2}\end{array}$ & $0.01 \pm 0.2$ & $0.19 \pm 3.1$ & $0.14 \pm 0.1$ & $2.29 \pm 2.1$ & $0.55 \pm 0,1$ & $9.65 \pm 2.6$ \\
\hline Blank = non imprinted & $0.04 \pm 0.1$ & $0.7 \pm 2.3$ & $0.05 \pm 0.2$ & $0.84 \pm 2.8$ & $0.14 \pm 0.1$ & $2.32 \pm 2.0$ \\
\hline
\end{tabular}

${ }^{a}$ The number of imprints per unit area was derived from optical microscopy. The strongest response is encountered when the template and target are identical as highlighted in yellow on the diagonal of the matrix. As compared to these "specific" responses, the cross reactions between noncomplementary imprints and cell types are insignificant. Response data for a blank polymer layer, corresponding to a zero effect within error bars, are given for comparison (grey-shaded fields).

cell types. Peripheral blood mononuclear cells (PBMC) were isolated from blood samples of a healthy female subject using a Ficoll separation technique. In order to remove unwanted proteins from the medium, the cells were washed with PBS in three steps. All ATCC cell cultures were ordered at LGC Standards S.a.r.l., Molsheim Cedex, France.

2.4. Surface Characterization of SIPs. The optical analysis of the imprinted polyurethane layers was performed with an Axiovert 40 inverted optical microscope (Carl Zeiss, Jena, Germany). Atomic force microscopy (AFM) measurements were performed in noncontact mode (NCM) using a NX 10 AFM (Park Instruments, Suwon, Korea). Standard pyramidal-shaped silicon nitride $\left(\mathrm{Si}_{3} \mathrm{~N}_{4}\right)$ cantilever tips with a length of $125 \mu \mathrm{m}$ and a nominal force constant of $40 \mathrm{~N} / \mathrm{m}$ were employed (ST Instruments, Sliedrecht, The Netherlands). Topography, NCM-phase, and NCM-amplitude were recorded across typical scanning areas of $45 \mu \mathrm{m} \times 45 \mu \mathrm{m}$. Both optical analysis and AFM imaging were performed in air at ambient temperature. The surface coverage of the polyurethane layers with cell imprints was determined on the basis of the optical micrographs analyzed with the software package Image J 1.44P (National Institute of Health, Bethesda, U.S.A.).

\section{RESULTS AND DISCUSSION}

3.1. Concept of Device for Specific Cell Detection and Identification. The general principle of the heat transfer method is shown in Scheme 1 (technical details are given in section 2.1 of Experimental Methods). The central element of the platform consists of an adjustable heat source attached to a copper block that transfers a thermal current trough an aluminum chip $\left(\sim 1\right.$ by $\left.1 \mathrm{~cm}^{2}\right)$ covered with a thin layer $(\sim 1.1$ $\mu \mathrm{m})$ of cell-imprinted polyurethane. Details of the surface imprinting of polyurethane (PU) are summarized in section 2.2 of Experimental Methods. During measurements, the temperature underneath the aluminum chip, $T_{1}$, is stabilized at 37.00 ${ }^{\circ} \mathrm{C}$ with a PID controller, and the temperature, $T_{2}$, in the liquid compartment above the polyurethane layer, is monitored. From the temperature difference $T_{1}-T_{2}$ and the required heating power $P$ to keep the copper block at $37.00{ }^{\circ} \mathrm{C}$, one can derive the heat transfer resistance $R_{\mathrm{th}}=\left(T_{1}-T_{2}\right) / P$ (see Figure $\mathrm{S} 1$, Supporting Information and refs 23,33). The contact area between the chip and the liquid compartment was $28 \mathrm{~mm}^{2}$, and we obtained $R_{\mathrm{th}}=4.2{ }^{\circ} \mathrm{C} / \mathrm{W}$ with a blank aluminum chip. Covering this chip with a nonimprinted polyurethane layer resulted in a typical $\mathrm{R}_{\mathrm{th}}$ increase of $2.0{ }^{\circ} \mathrm{C} / \mathrm{W}$. In the case of the imprinted PU layers, we found $R_{\mathrm{th}}$ values close to $6.0{ }^{\circ} \mathrm{C} / \mathrm{W}$.
Therefore, we suggest that the imprinted cavities, where the PU film is thinner, form preferential heat transport channels (see the model calculations in Figure S2, Supporting Information). Blocking these channels with cells should cause a measurable increase of $R_{\mathrm{th}}$ as schematically illustrated in Scheme $1 \mathrm{~b}$.

3.2. Characterization of Cell-Imprinted Polyurethane Layers. For the proof-of-principle experiments, SIP layers were synthesized with three cell types. NR8383 cells (rat alveolar macrophages) and RAW 264.7 cells (mouse leukemic monocyte macrophages) have both a spherical shape with diameters of $\approx 25 \mu \mathrm{m}$ (NR8383) and $\approx 15 \mu \mathrm{m}$ (RAW 264.7). This offers the possibility to assess the selectivity of the concept while imprints were also made with yeast cells (Saccharomyces cerevisiae) characterized by a diameter of only $6 \mu \mathrm{m}$. Previously, it was reported that recognition of cells by imprints is assisted by weak chemical bonds in addition to the complementarity in size. ${ }^{16}$ To confirm this, we prepared also SIPs with inorganic silica beads ( $15 \mu \mathrm{m}$ diameter) lacking surface functional groups. The experiments on human cells included the breast cancer cell line MCF-7, immortalized T-lymphocyte cell line Jurkat, and peripheral blood mononuclear cells (PBMC). Details about the cells culturing are given in section 2.3 of Experimental Methods.

All polymer surfaces imprinted with the different cell types were characterized by optical microscopy in order to determine the areal density of imprints. As an example, we found 8,000 imprints per $\mathrm{cm}^{2}$ for NR8383 and 25,000 per $\mathrm{cm}^{2}$ in case of MCF-7. Variations in the imprint density are related to the adherence behavior of the cell types under study; all coverage data are summarized in the Results and Discussion section. Figure 1a shows a typical optical micrograph of MCF-7 imprints, indicating the $20 \mu \mathrm{m}$ diameter of this cell type. Optical images of SIPs imprinted with other template cells are given in Figure S3 of the Supporting Information. A 3D image of a single MCF-7 imprint obtained by atomic force microscopy (AFM) is shown in Figure 1b. For more information on the imaging techniques we refer to section 2.4 of Experimental Methods. The AFM analysis demonstrates that the imprint is rather shallow with a depth of $500 \mathrm{~nm}$ below the surface of the polyurethane layer, which had a total thickness of $1.2 \mu \mathrm{m} \pm 0.1$ $\mu \mathrm{m}$ as determined by profilometry.

3.3. Proof-of-Principle: Selective Detection of Rodent Macrophages. Figure 2 comprises cross-selectivity experi- 

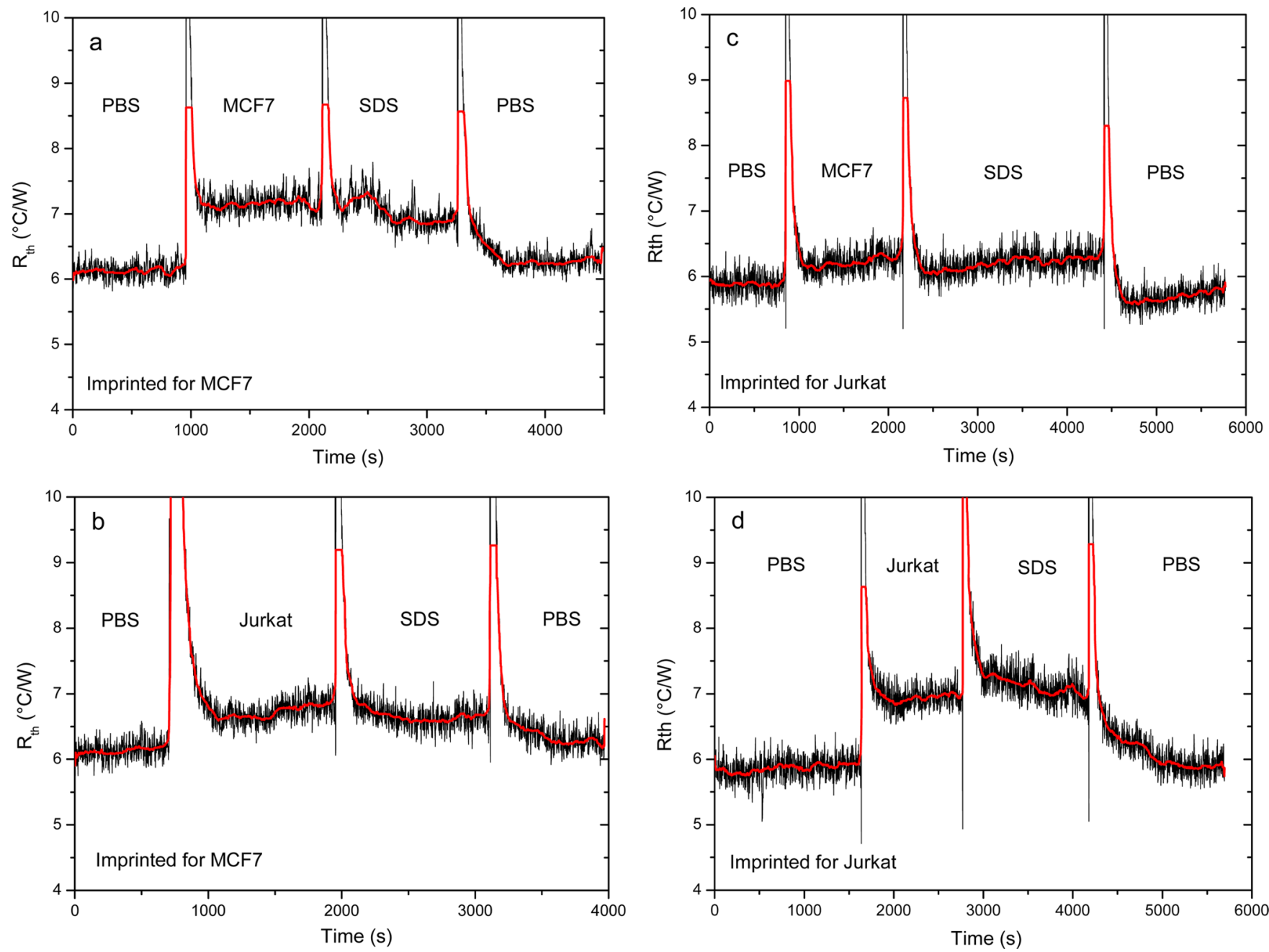

Figure 3. Detection of human cancer cells in a cross-selectivity setting (proof-of-application). The sensor device was used to discriminate between breast cancer cells (MCF-7) and an immortalized line of leukemic T-lymphocytes (Jurkat cells). SIPs were created for both cell types, and their $R_{\text {th }}$ response to each of the two cell lines was studied. Measurements were performed analogous to the protocol employed in Figure 2. (a) Time dependence of the thermal resistance obtained with a MCF-7 imprinted layer when exposed to a MCF-7 suspension. (b) Thermal response of the same layer in combination with Jurkat cells: The data suggest a moderate nonspecific absorption of Jurkat cells by the MCF-7 imprints. (c) A weak, albeit measurable, response of the heat transfer resistance occurs when MCF-7 cells bind nonspecifically to a Jurkat-imprinted polyurethane layer. (d) Selective recognition occurs when Jurkat cells bind to this Jurkat-imprinted SIP layer.

ments performed with NR8383 and RAW cells in combination with the respective imprints. Both cell types were suspended in PBS $(\mathrm{pH} 7.4)$ at a concentration of $1.0 \times 10^{6}$ cells $/ \mathrm{mL}$. The work flow in all experiments was identical; therefore, we focus first on the recognition of NR8383 cells by NR8383 imprints as shown in Figure 2a. In the initial state, the liquid compartment is filled with PBS buffer, and the thermal resistance is stable at $R_{\mathrm{th}}=5.9 \pm 0.2^{\circ} \mathrm{C} / \mathrm{W}$. The data shown are raw unfiltered data, and the noise level is induced by short-term fluctuations of the heating power $P$. Next, NR8383 cells were introduced $(2 \mathrm{~mL}$ liquid volume), and $R_{\mathrm{th}}$ rises to a new equilibrium at $7.0 \pm 0.2$ ${ }^{\circ} \mathrm{C} / \mathrm{W}$ upon addition of these target cells. This corresponds to an $R_{\text {th }}$ increase of $20 \%$, which is substantially higher than the noise level on the signal (4\%). The overshooting of the $R_{\mathrm{th}}$ signal upon flushing in the cell solution (originally at ambient temperature) is a temporary effect and vanishes as soon as the temperature distribution is again under equilibrium conditions. Then, the liquid compartment was flushed with $4 \mathrm{~mL}$ of $0.1 \%$ SDS (sodium-dodecyl sulfate solution) in order to lyse the cell membranes, leaving $R_{\mathrm{th}}$ at an almost constant level. Finally, the system was flushed with PBS to remove the cell residues and $R_{\mathrm{th}}$ comes back to its initial value of $6{ }^{\circ} \mathrm{C} / \mathrm{W}$. This type of cycle can be repeated for at least six times, indicating that SIP layers are reusable as documented in Figures S4 and S5 of the Supporting Information.

Exposing an NR8383-imprinted layer to a RAW cell suspension (Figure $2 \mathrm{~b}$ ) shows no specific response, except for a minor signal drift from 5.9 to $6.2^{\circ} \mathrm{C} / \mathrm{W}$. Also, when RAWimprinted layers are exposed to a NR8383 suspension (Figure 2c), cross-selectivity effects remain below the experimental resolution. However, the RAW SIPs do bind RAW cells as shown in Figure $2 \mathrm{~d}$, and the corresponding change of $R_{\mathrm{th}}(\approx$ $14 \%)$ is comparable to the recognition of NR8383 cells by NR8383-imprinted layers (Figure 2a). The absolute and relative $R_{t h}$ values are calculated as the response in $R_{t h}$ divided by the baseline $R_{\mathrm{th}}$ value before addition of the cells; this number is then multiplied by 100 to obtain a percentual response. The $R_{\mathrm{th}}$ changes compared to the starting conditions are summarized in Table 1. 
Table 2. Data Obtained in a Similar Manner as the Data Summarized in Table 1 (standardized cell concentration, no washing) with Human Cancer Cell Lines MCF-7 and Jurkat as well as PBMCs of a Healthy Volunteer ${ }^{a}$

\begin{tabular}{|c|c|c|c|c|c|c|}
\hline \multirow[t]{2}{*}{$\begin{array}{l}\text { Target } \\
\text { Concentration } \\
\end{array}$} & \multicolumn{2}{|c|}{$\begin{array}{l}\text { MCF-7 } \\
1 \cdot 10^{6} \pm 9 \cdot 10^{4} \text { cells } / \mathrm{ml}\end{array}$} & \multicolumn{2}{|c|}{$\begin{array}{l}\text { Jurkat } \\
1 \cdot 10^{6} \pm 7 \cdot 10^{4} \text { cells } / \mathrm{ml}\end{array}$} & \multicolumn{2}{|c|}{$\begin{array}{l}\text { PBMC } \\
1 \cdot 10^{6} \pm 1 \cdot 10^{5} \text { cells } / \mathrm{ml}\end{array}$} \\
\hline & $\Delta$ Rth $\left({ }^{\circ} \mathrm{C} / \mathrm{W}\right)$ & $\%$ response & $\Delta$ Rth $\left({ }^{\circ} \mathrm{C} / \mathrm{W}\right)$ & $\%$ response & $\Delta$ Rth $\left({ }^{\circ} \mathrm{C} / \mathrm{W}\right)$ & $\%$ response \\
\hline $\begin{array}{l}\text { Imprint: MCF-7 } \\
24,840 \pm 3,520 \text { cavities } / \mathrm{cm}^{2}\end{array}$ & $1.09 \pm 0.1$ & $18.0 \pm 2.1$ & $0.33 \pm 0.1$ & $5.0 \pm 2.3$ & $0.02 \pm 0.1$ & $0.4 \pm 1.7$ \\
\hline $\begin{array}{l}\text { Imprint: Jurkat } \\
22,550 \pm 2,780 \text { cavities } / \mathrm{cm}^{2}\end{array}$ & $0.26 \pm 0.1$ & $4.4 \pm 2.4$ & $1.15 \pm 0.2$ & $19.7 \pm 2.7$ & $0.27 \pm 0.1$ & $4.4 \pm 1.1$ \\
\hline $\begin{array}{l}\text { Imprint: PBMC } \\
16,430 \pm 2,950 \text { cavities } / \mathrm{cm}^{2}\end{array}$ & $-0.08 \pm 0.1$ & $-1.4 \pm 1.7$ & $0.31 \pm 0.1$ & $5.2 \pm 2.3$ & $0.75 \pm 0.1$ & $12.6 \pm 2.1$ \\
\hline Blank $=$ non imprinted & $0.05 \pm 0.2$ & $0.9 \pm 3.0$ & $0.08 \pm 0.1$ & $1.3 \pm 3.0$ & $0.07 \pm 0.1$ & $1.2 \pm 1.8$ \\
\hline
\end{tabular}

${ }^{a}$ Again, the strongest response is found on the diagonal where the target cells and the imprints are matching while nonspecific absorbance to blank polyurethane is absent. However, a nonspecific response cannot be ignored as exemplified with Jurkat cells. The Rth increase measured with Jurkatimprinted layers is $20 \%$ upon recognition of Jurkat cells, while there is also an increase of $5 \%$ when MCF-7 or PBMC imprints are exposed to the same Jurkat cell concentration.

Furthermore, NR8383 cells were used to determine the dose-response characteristics of the sensor system based on a series of dilution experiments given in Figure S5 of the Supporting Information. The sensor signal saturates with 100,000 cells $/ \mathrm{mL}$, which is 10 -fold lower than the concentration of $10^{6}$ cells $/ \mathrm{mL}$ used in all measurements. The resolution of the readout system is, after data filtering, better than $\pm 0.1{ }^{\circ} \mathrm{C} / \mathrm{W}$, and the 3 -fold of the noise level is reached with 30,000 cells $/ \mathrm{mL}\left(0.3{ }^{\circ} \mathrm{C} / \mathrm{W}\right)$. The reference experiment with a nonimprinted PU layer gave for NR8383, as well as for RAW cells, an $R_{\text {th }}$ change on the order of $1 \%$, indicating that there is no relevant sticking effect of cells to nonimprinted (blank) polyurethane. This holds also when a blank layer is exposed to yeast cells. These measurements are shown in Figure S6 of the Supporting Information, and the data are included in Table 1.

Regarding the experiments with yeast cells, we can state that yeast cells bind exclusively to yeast imprints and neither to RAW nor to NR8383 imprints. Vice versa, these cell types show no sticking to yeast-imprinted layers as expected; all data are summarized in Figure S7 of the Supporting Information and represented in Table 1 . We note that the $R_{\text {th }}$ change of $10 \%$ when binding yeast to yeast imprints is lower than in the case of macrophages despite the fact that the yeast imprints are especially numerous with more than 100,000 per $\mathrm{cm}^{2}$, while the concentration of target cells was identical. We relate the moderate $R_{\mathrm{th}}$ increase to the small dimensions of these cells (6 $\mu \mathrm{m})$, covering a smaller lateral area after binding and being less extended along the heat flow direction, thus corresponding to a less efficient thermal insulator. The recognition experiment was also performed with silica beads and their corresponding imprints. In contrast to the macrophages and yeast cells, which still stick to their imprints after SDS rinsing, the behavior of silica is different. SDS rinsing removes the beads, and the $R_{\mathrm{th}}$ value recovers instantly to the sensor baseline (Figure S8, Supporting Information). Hence, we conclude that the recognition of cells involves the formation of weak chemical bonds in addition to geometrical matching. ${ }^{16}$

3.4. Proof-of-Application: Selective Detection of Human Cancer Cells. In order to assess whether the concept allows distinguishing human cancer cells from each other and from healthy blood cells, SIPs were created for MCF-7, Jurkat, and PBMCs derived from a healthy volunteer. PBMC suspensions are a mixture of $\mathrm{T}$ - and B-lymphocytes, monocytes, and macrophages. Figure 3 summarizes the recognition of the MCF-7 cells by MCF-7 imprints (Figure 3a), the nonspecific recognition of Jurkat cells by MCF-7 imprints (Figure 3b), and the corresponding data on Jurkat imprints exposed to either MCF-7 or to Jurkat cells (Figure 3c,d). Numerical data on the absolute and relative $R_{\mathrm{th}}$ changes are summarized in Table 2, including also the PBMC reference data (as template and target) and the nonspecific adsorption to nonimprinted polyurethane. The underlying experiments are given in Figures S6 and S9 of the Supporting Information. First, the recognition of MCF-7 cells by MCF-7 imprints and the recognition of Jurkat cells by Jurkat imprints go along with a significant $R_{\text {th }}$ increase by almost $20 \%$ in both cases. For PBMC, the specific response with $\mathrm{PBMC}$ imprints is weaker, only $14 \%$, owing to the fact that PBMC is a mixed cell population.

However, there are minor but measurable cross-selectivity effects. $R_{\text {th }}$ increases of $4-5 \%$ are observed in the following cases: (i) MCF-7 cells in combination with Jurkat imprints, (ii) Jurkat cells in combination with MCF-7 and PBMC imprints, and (iii) PBMC with the Jurkat imprints. The cross selectivity of Jurkat imprints for PBMC and PBMC imprints for Jurkat cells can be understood from the fact that Jurkat cells are an immortalized T-cell line while PBMC consists partly of healthy T-cells. The cross recognition between Jurkat and MCF-7 seems surprising, but different types of cancer cells exhibit similar membrane properties and functional groups (glycolysation pattern) associated with, for example, the MUC1 membrane protein. ${ }^{27-30}$ MCF-7 and PBMC show no cross selectivity at all. These are different cell types, and there are no cancer-related features on the PBMC membranes. In general, the binding of target cells to their corresponding SIP results in an at least 4 times stronger rise of $R_{\mathrm{th}}$ as compared to the nonspecific recognition of competitor cells. This way, the proposed method is able to distinguish between different cell types if we postulate that a sensor response by $5 \%$ or less is due to a nonspecific effect. However, the amount of cancer cells such as MCF-7 is not known beforehand in blood samples, and nonspecific binding of PBMC may be dominant over specific MCF-7 recognition. Therefore, we will aim now at a strategy to 

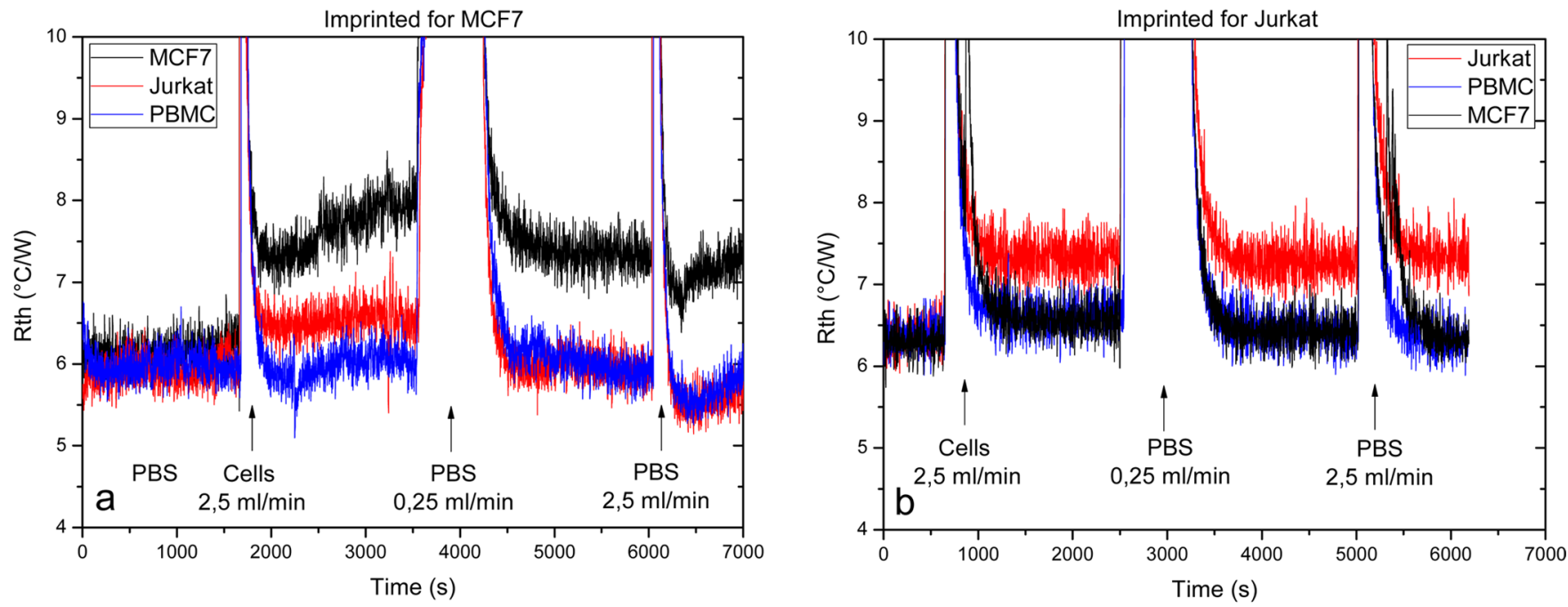

Imprinted for PBMC

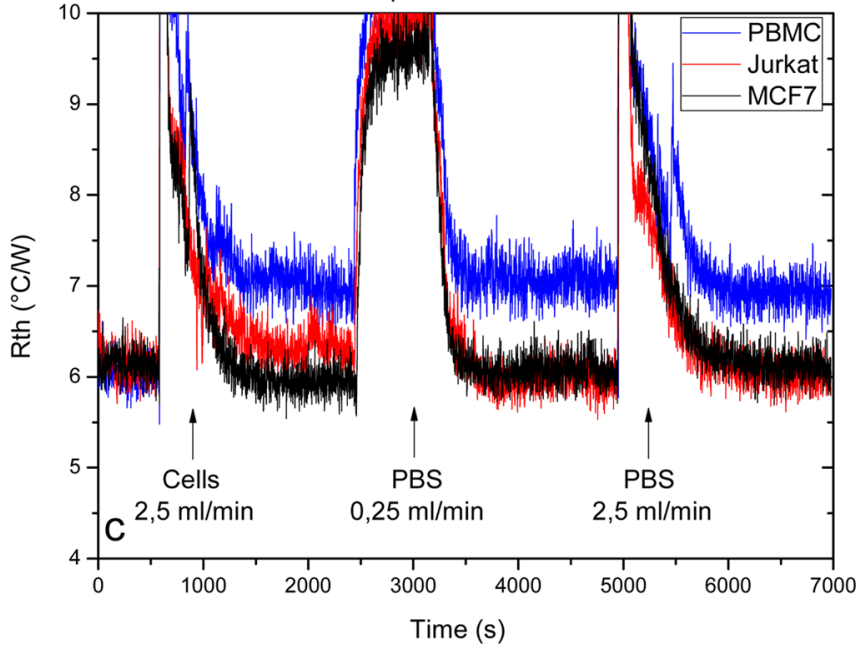

Figure 4. Enhancement of the selectivity by PBS rinsing using an automated medium exchange system. (a) Thermal response with an MCF-7 imprinted SIP toward MCF-7 cells (black line), Jurkat cells (red line), and PBMC (blue line). Mild rinsing with cell-free PBS was performed at a flow rate of $0.25 \mathrm{~mL} / \mathrm{min}$, and stringent rinsing was done at $2.5 \mathrm{~mL} / \mathrm{min}$. Rinsing brings the cross-selective response to Jurkat and PBMC cells back to the sensor baseline. (b) Thermal response of a Jurkat-imprinted SIP toward Jurkat, PBMC, and MCF-7 cells with consecutive rinsing; the color code is identical to that in panel (a). (c) Thermal response of a PBMC-imprinted SIP toward PBMC, Jurkat, and MCF-7 cells. The color code and rinsing steps are identical to those of panels (a) and (b). Also panels (b) and (c) show that rinsing reestablishes the sensor baseline for cells that are noncomplementary to the imprints; the signal is unaffected in all cases where cells and imprints are complementary $(a, b, c)$.

boost the selectivity ratio, allowing discriminating sharply between MCF-7, Jurkat, and PBMC.

3.5. Enhancing Selectivity of Cell Recognition. On the basis of the idea that a nonspecific sensor response stems mainly from geometrical matching between cells and imprints rather than from chemical interactions, we developed a rinsing technique for selectivity enhancement. The sensor setup (Figure 1a) was connected to a computer-controlled flow system, allowing administering cell suspensions and rinsing fluid (pure PBS) at defined moments with defined flow rates. Figure 4a summarizes data obtained all with a single MCF-7 SIP layer. When MCF-7 cells are introduced at a rate of 2.5 $\mathrm{mL} / \mathrm{min}(3 \mathrm{~mL}$ in total, $72 \mathrm{~s}), R_{\mathrm{th}}$ increases from 6.0 to $7.5^{\circ} \mathrm{C} /$ $\mathrm{W}$ under static conditions. The flushed-in volume exceeds the initial PBS filling of the liquid compartment by almost 30 times, and $R_{\text {th }}$ runs up to $8.0^{\circ} \mathrm{C} / \mathrm{W}$, possibly due to sedimentation on top of the specific recognition. A mild rinsing step with cell-free PBS (flow rate $0.25 \mathrm{~mL} / \mathrm{min}$, total volume $3 \mathrm{~mL}, 12 \mathrm{~min}$ ) brought the $R_{\mathrm{th}}$ response back to $7.5^{\circ} \mathrm{C} / \mathrm{W}$, and this remained stable even after stringent rinsing with the same PBS volume (flow rate of $2.5 \mathrm{~mL} / \mathrm{min}$ for $72 \mathrm{~s}$ ). After redoing this sequence with $\mathrm{PBMC}$, the sensor baseline at $6.0^{\circ} \mathrm{C} / \mathrm{W}$ did not change over time. The same experiment with Jurkat cells gave a nonspecific increase of $0.5{ }^{\circ} \mathrm{C} / \mathrm{W}$ after introducing the Jurkat solution, while already the first rinsing reestablished the baseline, and there was no further change after stringent rinsing. This means that the shear forces exerted by the liquid flow are sufficient to break the nonspecific sticking between cells and imprints in case that chemical complementarities are missing.

The analogous experiment with a Jurkat-imprinted SIP layer (Figure $4 \mathrm{~b}$ ) showed a selective permanent recognition of Jurkat cells, while the nonspecific response to MCF cells and PBMC ( $+0.5{ }^{\circ} \mathrm{C} / \mathrm{W}$ in both cases) vanished after rinsing. Similarly, also the nonspecific response of Jurkat cells to PBMC imprints $\left(+0.4{ }^{\circ} \mathrm{C} / \mathrm{W}\right)$ is canceled out by this method as shown in Figure $4 \mathrm{c}$. All binding and rinsing data for the cross-selectivity matrix of the three different imprint types with the three types 

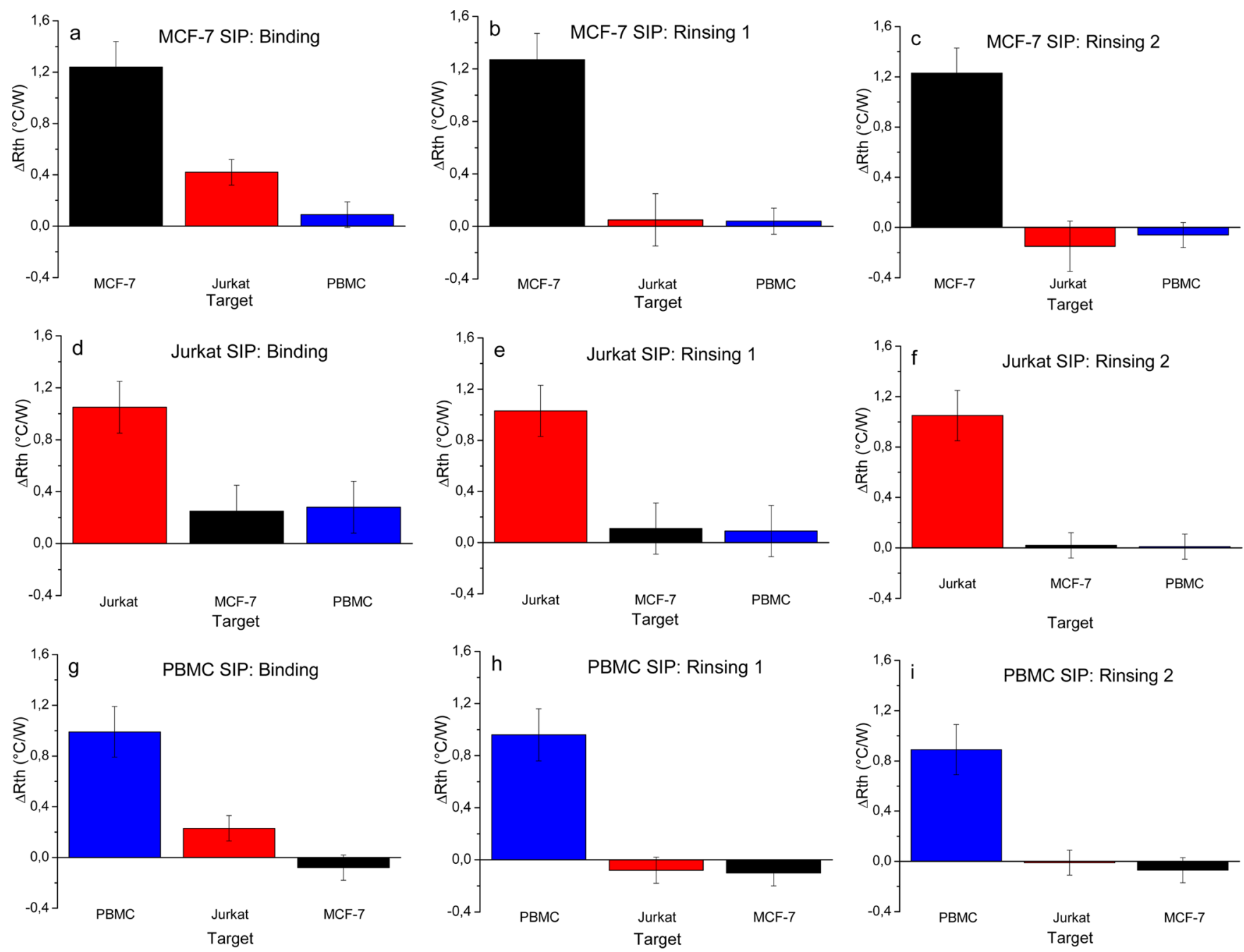

Figure 5. Bar chart representation of the change in thermal resistance $\Delta R_{\text {th }}$ observed with three different types of SIPs upon exposure to MCF-7, Jurkat, and PBMC cells during binding and the consecutive washing steps. (a) MCF-7 SIP with MCF-7 cells (black), Jurkat cells (red), and PBMC (blue) during binding. (b) MCF-7 SIP after the first rinsing (color code identical to that of panel (a)) and after the second rinsing (c). (d,e,f) Thermal resistance change upon binding and washing steps obtained with the Jurkat SIP. (g,h,i) Thermal resistance changes upon binding and washing steps measured with the PBMC-imprinted SIP. Within error bars, the nonspecific response is completely suppressed after the second washing step (c,f,i). Note that in case of PBMC imprints (i), the specific signal for PBMC target cells (mixed cell population) has moderately decreased as compared to the signal height obtained after the binding phase $(\mathrm{g})$. Numerical representation of all data can be found in Table S2 of the Supporting Information.

of target cells are condensed as bar charts in Figure 5. After the second, "stringent" rinsing step, the cross-response is smaller than the error bars defined by the noise level. At the same time, the $R_{\mathrm{th}}$ increase of SIPs, which have selectively rebound their template molecules, remains constant, demonstrating the efficiency of rinsing-based selectivity enhancement.

\section{CONCLUSIONS}

The results suggest that surface imprinting of cells into polymer layers (creating whole cell receptors) and the readout based on HTM form a marriage parfait. The combination of both has the potential to evolve into a specific low-cost diagnostic tool for the detection and follow-up of diseases going along with certain phenotypes of blood cells. Generally speaking, the assay can be performed in an automated way in a lab-on-chip device, and one may also think of environmental applications such as the detection of pathogenic bacteria in drinking water. At the receptor side, the SIP layers are reusable many times, and their selective binding capacity can be regenerated by washing with
SDS and buffer solutions. For a stable binding between cells and imprints, geometrical congruency alone is insufficient, and also a complementarity of chemical functionalities is required. This way, the selective binding of cells can be achieved without using antibodies against certain cell membrane groups, and this is a major benefit in terms of costs, reproducibility, and sensor regeneration capacity.

At the side of the detection system, HTM requires only a minimum of instrumentation to monitor the temperature underneath and above the surface-imprinted polymer layer. Such a thermometric technique is insensitive to environmental and electronic disturbances. The HTM concept also allows for multiplexing toward sensor arrays consisting of chips with several regions imprinted with a variety of target cell types. Furthermore, cell recognition by SIPs is of course also possible with impedance spectroscopy and quartz crystal microbalances, ${ }^{1,16}$ but HTM does not rely on the electrical conductivity or piezoelectric properties of the platform material because any solid material can serve as a platform provided it 
does not inhibit the heat flow through the SIP layer. In this sense, HTM can also be combined with an impedimetric or QCM readout in a single device because the transducing principles (here, heat flow) are mutually independent. In our experiments, aluminum was the first choice, but other metals or oxides with good heat conductivity should perform similarly well. Note that the cells had no direct contact with the aluminum chip due to the polyurethane interlayer.

As an explanation for the $R_{\mathrm{th}}$ increase upon binding of cells in the imprinted cavities, we propose the local blocking of heat transfer from the polyurethane layer to the liquid compartment. The total surface fraction covered with imprint-bound cells is below $10 \%$, but the cell diameter of typically $10-20 \mu \mathrm{m}$ exceeds the $1 \mu \mathrm{m}$ thickness of the PU layers by a decade. Therefore, it is reasonable that the $R_{\mathrm{th}}$ change upon cell recognition (typically $1{ }^{\circ} \mathrm{C} / \mathrm{W}$ ) is similar to the $R_{\mathrm{th}}$ change observed when covering the blank aluminum with polyurethane ( $R_{\mathrm{th}}$ change of $2{ }^{\circ} \mathrm{C} / \mathrm{W}$ ). We point out that the (reversible) $R_{\mathrm{th}}$ step upon cell recognition is persistent and not fading away over time. This is intrinsically different from calorimetric biosensors that are measuring the transient thermal energy associated with the binding of target entities by receptors. ${ }^{34} \mathrm{~A}$ second phenomenon with potential impact on the data is the enhanced thermal conductivity of "nanofluids". ${ }^{35}$ However, we can rule out contributions from this effect because it only occurs for particles with nanometer size, while the cell suspensions always resulted in either an increasing or a constant $R_{\mathrm{th}}$ value in the sensor device.

To benchmark the $R_{\mathrm{th}}$-based technique of cancer cell detection with the state of the art, we mention recent reports describing the identification of circulating tumor cells by image cytometry. ${ }^{36,37}$ According to this work, it is feasible to detect concentrations as low as 1 cell per $\mathrm{mL}$ after purification of blood samples and targeting the cells with fluorescently labeled antibodies. The HTM technique presented here is a very first demonstration of the concept and not yet optimized toward ultralow detection limits. However, special benefits are the lowcost label-free readout apparatus, and cells are detected through their integral membrane properties, which do not need to be known in detail. Furthermore, the technique can be automated and digitalized and does not require an image analysis by an expert. Regarding other label-free techniques, MCF-7 cells were detected by amperometric, ${ }^{38}$ magnetoelastic, ${ }^{39}$ and microgravimetric sensors. ${ }^{40}$ These concepts require cell concentrations in the range of $10^{4}-10^{6}$ cells $/ \mathrm{mL}$ in buffer, while there is no information on the selectivity. The detection of Jurkat cells is documented by using antibodies as recognition elements and a photonic crystal readout principle. ${ }^{41}$ Typical numbers are $2 \times 10^{5}$ cells per assay, and the concept allowed to discriminate between two different Jurkat cell lines.

The final goal is selective detection of specific disease-related cells in blood, and their absolute concentration will generally be lower than the total cell count. A first up-concentration can then be accomplished by filtration, and there are microfluidic approaches specifically designed to extract cancer cells from blood. $^{21,22}$ Furthermore, the detection limit of our system (below $3 \times 10^{4}$ cells $/ \mathrm{mL}$ ) can be lowered by electronic noise reduction, design modifications, and increasing the number of cell imprints per unit area; a 4-fold increase toward 100,000 MCF-7 or Jurkat imprints per $\mathrm{cm}^{2}$ seems realistic. Finally, we observed that cells, which are only weakly and nonspecifically bound, are released from the SIP layer by rinsing, while the true target cells remain sticking in the imprints. Assuming that a recognition experiment is conducted in a continuous closedloop operation with a steady flow, cross selectivity can be suppressed while the actual target cells become gradually enriched on the SIP-layer, even if their absolute concentration is low as compared to competitor cells.

\section{ASSOCIATED CONTENT}

\section{Supporting Information}

Supporting Information to this document contains additional graphs and tables and theoretical models that are referred to in the text. This material is available free of charge via the Internet at http://pubs.acs.org.

\section{AUTHOR INFORMATION}

\section{Corresponding Author}

*Phone: +32-11-26.88.95. Fax: +32-11-26.88.99. E-mail: patrick.wagner@uhasselt.be.

\section{Author Contributions}

K.E. prepared all cell-imprinted polymer layers and was responsible for culturing the animal cells in cooperation with S.T., J.F.J.B., and J.J.A.H. The heat transfer device was designed by B.v.G. All heat transfer measurements were performed by B.v.G. in cooperation with K.E. AFM imaging was performed by K.L.J.M in cooperation with S.P. Optical analysis of the samples was done by K.E. together with T.V., who also produced the PDMS stamps. Biological assistance and guidance was provided by V.S., J.J.A.H., A.E., and M.J.A.P.D., who also gave insight in future possible applications of the concept. A.E. contributed in terms of optical characterization and provided input to the synthesis of the polyurethane layers in cooperation with T.J.C. B.v.G. and K.E. interpreted the heat transfer data in close cooperation with P.W. and W.D.C. Insights in technical improvements of the setup were provided by P.W. and W.D.C. The manuscript was jointly written by P.W., K.E., and B.v.G. These authors contributed equally. All authors have given approval to the final version of the manuscript.

\section{Author Contributions}

$\nabla$ Both authors contributed equally.

\section{Notes}

The authors declare no competing financial interest.

\section{ACKNOWLEDGMENTS}

This work was financed by the Life Science Initiative of the Province of Limburg, by the Special Research Funds BOF of Hasselt University, the Research Foundation Flanders FWO (projects G.0B.6213.N and 'Methusalem Nano') and by the Interreg IV-A project MicroBioMed (European Funds for Regional Development). Technical support by J. Baccus, L. De Winter, J. Soogen and J. Mertens in building the mechanical and electronic systems components is greatly appreciated. The authors are also grateful to Prof. J. D'Haen for scanning electron microscopy and C. Bocken for valuable advice on handling, culturing, and isolating the human cell lines.

\section{REFERENCES}

(1) Haupt, K.; Mosbach, K. Chem. Rev. 2000, 100, 2495-2504.

(2) Piletsky, S. A.; Turner, A. P. F. Electroanalysis 2002, 13, 317-323.

(3) Peeters, M.; Troost, F. J.; van Grinsven, B.; Horemans, F.; Alenus, J.; Murib, M. S.; Keszthelyi, D.; Ethirajan, A.; Thoelen, R.; Cleij, T. J.; Wagner, P. Sens. Actuators, B 2012, 171-172, 602-610. 
(4) Peeters, M.; Troost, F. J.; Mingels, R. H. G.; Welsch, T.; van Grinsven, B.; Vranken, T.; Ingebrandt, S.; Thoelen, R.; Cleij, T. J.; Wagner, P. Anal. Chem. 2012, 85, 1475-1483.

(5) Thoelen, R.; Vansweevelt, R.; Duchateau, J.; Horemans, F.; D’Haen, J.; Lutsen, L.; Vanderzande, D.; Ameloot, M.; vandeVen, M.; Cleij, T. J.; Wagner, P. Biosens. Bioelectron. 2008, 23, 913-918.

(6) Vlatakis, G.; Andersson, L. I.; Müller, R.; Mosbach, K. Nature 1993, 361, 645-647.

(7) Shi, H.; Tsai, W. B.; Garrison, M. D.; Ferrar, S.; Ratner, B. D. Nature 1999, 398, 593-597.

(8) Hayden, O.; Lieberzeit, P. A.; Blaas, D.; Dickert, F. L. Adv. Funct. Mater. 2006, 16, 1269-1278.

(9) Alexander, C.; Vulfson, E. V. Adv. Mater. 1997, 9, 751-755.

(10) Cohen, T.; Starosvetsky, J.; Cheruti, U.; Armon, T. Int. J. Mol. Sci. 2010, 11, 1236-1252.

(11) Qi, P.; Wan, Y.; Zhang, D. Biosens. Bioelectron. 2013, 39, 282288.

(12) Jenik, M.; Schirhagl, R.; Schirk, C.; Hayden, O.; Lieberzeit, P.; Blaas, D.; Paul, G.; Dickert, F. L. Anal. Chem. 2009, 81, 5320-5326.

(13) Jenik, M.; Seifner, A.; Lieberzeit, P. A.; Dickert, F. L. Anal. Bioanal. Chem. 2009, 394, 523-528.

(14) Hayden, O.; Dickert, F. L. Adv. Mater. 2001, 13, 1480-1483.

(15) DePorter, S. M.; Lui, I.; McNaughton, B. R. Soft Matter 2012, 8, 10403-10408.

(16) Hayden, O.; Mann, K. J.; Krassnig, S.; Dickert, F. L. Angew. Chem., Int. Ed. 2006, 45, 2626-2629.

(17) Held, M.; Schumann, W.; Jahreis, K.; Schmidt, H. L. Biosens. Bioelectron. 2002, 17, 1089-1094.

(18) Bohrn, U.; Stütz, E.; Fuchs, K.; Fleisher, M.; Schöning, M. J.; Wagner, P. Sens. Actuator, B 2012, 175, 208-217.

(19) Bohrn, U.; Stütz, E.; Fleischer, M.; Schöning, M. J.; Wagner, P. Biosens. Bioelectron. 2013, 40, 393-400.

(20) Rahman, A. R. A.; Lo, C. M.; Bhansali, S. Sens. Actuator, B 2006, $118,115-120$.

(21) Han, K. H.; Han, A.; Frazier, A. B. Biosens. Bioelectron. 2006, 21, 1907-1914.

(22) Chen, J.; Lib, J.; Sun, Y. Lab Chip 2012, 12, 1753-1767.

(23) van Grinsven, B.; Vanden Bon, N.; Strauven, H.; Grieten, L.; Murib, M. S.; Jimenez Monroy, K. L.; Janssens, S. D.; Haenen, K.; Schöning, M. J.; Vermeeren, V.; Ameloot, M.; Michiels, L.; Thoelen, R.; De Ceuninck, W.; Wagner, P. ACS Nano 2012, 6, 2712-2721.

(24) Ferencik, M. In Handbook of Immunochemistry, 1st ed.; Chapman \& Hall: London, 1993; pp 22-49.

(25) Schenkel-Brunner, H. In Human Blood Groups, Chemical and Biochemical Basis of Antigen Specificity, 2nd ed.; Salvini-Plawen, A., Ed.; Springer: Heidelberg, 2000; pp 54-90.

(26) Mason, V. R. J. Am. Med. Assoc. 1922, 79, 1318-1320.

(27) Hollingsworth, M. A.; Swanson, B. J. Nat. Rev. Cancer 2004, 4, $45-60$.

(28) Gendler, S. J. J. Mammary Gland Biol. 2001, 6, 339-353.

(29) Zaretsky, J. Z.; Barnea, I.; Aylon, Y.; Gorivodsky, M.; Wreschner,

D. H.; Keydar, I. Mol. Cancer 2006, 5, 57.

(30) Mukherjee, P.; Tinder, T. L.; Basu, G. D.; Gendler, S. J. J. Leukocyte Biol. 2005, 77, 90-99.

(31) Kolodgie, F. D.; Narula, J.; Burke, A. P.; Haider, N.; Farb, A.; Hiu-Lang, Y.; Smialek, J.; Virmani, R. Am. J. Pathol. 2000, 157, 12591268.

(32) Blanc-Brude, O. P.; Teissier, E.; Castier, Y.; Lesèche, G.; Bijnens, A. P.; Daemen, M.; Staels, B.; Mallat, Z.; Tedgui, A. Arterioscler., Thromb., Vasc. Biol. 2007, 27, 901-907.

(33) Lenz, M.; Striedl, G.; Fröhler, U. In Thermal Resistance, Theory and Practice, Special Subject Book, January 2000, SMD Packages, 1st ed; Infineon Technologies AG: Munich, 2000; p 17.

(34) Lettau, K.; Warsinke, A.; Katterle, M.; Danielsson, B.; Scheller, F. W. Angew. Chem., Int. Ed. 2006, 45, 6986-6990.

(35) Keblinski, P.; Phillpot, S. R.; Choi, S. U. S.; Eastman, J. A. Int. J. Heat Mass Transfer 2002, 45, 855-863.
(36) Scholtens, T. M.; Schreuder, F.; Ligthart, S. T.; Swennenhuis, J. F.; Tibbe, A. G. J. T; Greve, J.; Terstappen, L. W. M. M. Cytometry, Part A 2011, 79A, 203-213.

(37) Scholtens, T. M.; Schreuder, F.; Ligthart, S. T.; Swennenhuis, J. F.; Greve, J.; Terstappen, L. W. M. M. Cytometry, Part A 2012, 81A, $138-148$.

(38) Zhao, J.; Yan, Y.; Zhu, L.; Li, X.; Li, G. Biosens. Bioelectron. 2013, $41,815-819$.

(39) Xiao, X.; Guoa, M.; Li, Q.; Cai, Q.; Yao, S.; Grimes, C. A. Biosens. Bioelectron. 2008, 24, 247-252.

(40) Marx, K. A.; Zhou, T.; Montrone, A.; McIntosh, D.; Braunhut, S. J. Anal. Biochem. 2005, 343, 23-34.

(41) Lin, B.; Li, P.; Cunningham, B. T. Sens. Actuator, B 2006, 114, 559-564. 